NASA Technical Memorandum 106207

AIAA-93-2106

\title{
Preliminary Investigation of High Power Microwave Plasmas for Electrothermal Thruster Use
}

John L. Power and Daniel J. Sullivan

Lewis Research Center

Cleveland, Ohio

Prepared for the

29th Joint Propulsion Conference and Exhibit cosponsored by the AIAA, ASEE, ASME, and SAE

Monterey, California, June 28-30, 1993 


\title{
PRELIMINARY INVESTIGATION OF HIGH POWER MICROWAVE PLASMAS FOR
}

\section{ELECTROTHERMAL THRUSTER USE}

\author{
John L. Power* and Daniel J. Sullivan ${ }^{* *}$ \\ National Aeronautics and Space Administration \\ Lewis Research Center \\ Cleveland, Ohio 44135
}

\begin{abstract}
$\underline{\text { Abstract }}$
Results are reported from preliminary tests to evaluate the high power microwave electrothermal thruster (MET) concept, which employs a free-floating plasma discharge maintained by applied continuous wave $(\mathrm{CW})$ microwave power to heat a propellant gas flow. Stable plasmas were created and maintained in helium $(\mathrm{He})$, nitrogen $\left(\mathrm{N}_{2}\right)$, and hydrogen $\left(\mathrm{H}_{2}\right)$ as propellants in both the $\mathrm{TM}_{011}$ and $\mathrm{TM}_{012}$ modes at discharge pressures from $10 \mathrm{~Pa}$ to $69 \mathrm{kPa}$. Reproducible starting conditions of pressure and power were documented for all the plasmas. Vortical inflow of the propellant gas was observed to cause the formation of onaxis "spike" plasmas. The conditions under which these plasmas form and unform were studied. Operation in the spike plasma condition enables maximum power absorption with minimum wall heating and offers maximum efficiency in heating the propellant gas. In the spike condition, plasmas of the three propellant gases were investigated in an open channel configuration to a maximum applied power level of $11.2 \mathrm{~kW}$ (in $\mathrm{N}_{2}$ ). Microwave power coupling efficiencies over 90 percent were routinely obtained at absorbed power levels up to $2 \mathrm{~kW}$. Magnetic nozzle effects were investigated using a superconducting solenoidal magnet to apply a high magnetic field to the plasmas in, and exiting from, the discharge tube.
\end{abstract}

\section{Nomenclature}

SI units presumed for all quantitites

velocity of
$\approx 2.998 \times 10^{8} \mathrm{~m} / \mathrm{sec}$

E electric field strength

E maximum amplitude of electric field strength

$\mathrm{E}_{01 \mathrm{p}}$ maximum on-axis electric field strength of $\mathrm{TM}_{01 \mathrm{p}}$ mode
$\mathbf{E}_{\boldsymbol{z}}, \mathbf{E}_{\phi}, \mathbf{E}_{\rho}$

$f_{r}$

$\mathbf{H}_{\mathrm{z}}, \mathbf{H}_{\phi}, \mathbf{H}_{\mathrm{p}}$

$\mathrm{h}$

I

$\mathrm{J}_{\mathbf{0}}, \mathrm{J}_{\mathbf{1}}$

$\mathrm{m}_{\mathrm{e}}$

$\mathrm{n}_{\mathrm{e}}$

$P$

$\mathrm{p}$

$p$

q

t

V

$\mathrm{v}_{\mathrm{p}}$

$z$

$\varepsilon$

$\varepsilon_{0}$

$\mu$

$\mu_{0}$ axial, azimuthal, and radial components of electric field

resonant frequency

axial, azimuthal, and radial components of magnetic field

cylindrical cavity length

current density

Bessel functions of zeroth and first order

electron mass, $\approx 9.11 \times 10^{-31} \mathrm{~kg}$

electron number density

electric power density

number of field half cycles in axial direction; subscript for $\mathrm{TM}_{01 \mathrm{p}}$ modes

pressure

electronic charge, $\approx 1.60 \times 10^{-19} \mathrm{C}$

time

voltage differential

phase velocity

axial distance

permittivity of cavity medium

permittivity of free space, $\approx 8.85 \times 10^{-12} \mathrm{C} / \mathrm{Vm}$

permeability of cavity medium

permeability of free space, $=4 \pi \times 10^{-7} \mathrm{H} / \mathrm{m}$

\footnotetext{
*Aerospace Engineer, NASA Lewis Research Center, member AIAA.

** Ph.D. Candidate, Department of Aerospace Engineering, The Pennsylvania State University, Student member AIAA.
} 


$\begin{array}{ll}v_{\mathrm{m}} & \text { collision frequency } \\ \rho & \text { radial distance } \\ \sigma & \text { plasma conductivity } \\ \chi_{01} & \text { first zero of } \mathrm{J}_{0} \text { Bessel function, } \approx 2.405 \\ \omega & \text { radian frequency of microwave field } \\ & \text { Introduction }\end{array}$

The MET concept employs a microwave plasma discharge maintained in a suitable applicator to heat a flowing propellant gas stream. The plasma discharge is created by $\mathrm{AC}$ induced breakdown of the propellant in a region of maximum electric power density. The plasma acts as an electrodeless resistive load which efficiently absorbs applied $\mathrm{CW}$ microwave power and converts it into thermal, internal, and radiant energy of the propellant gas. The heated propellant produced in the plasma region expands through a converging-diverging nozzle to produce the MET's thrust.

Applicators successfully investigated to date for the MET include the resonant cavity, ${ }^{1,2}$ the coaxial applicator, ${ }^{3}$ and the waveguide applicator. ${ }^{4}$ In all of these, breakdown of the propellant gas is induced under suitable conditions of pressure and applied microwave power, and the discharge is maintained as the pressure and power are raised to desired operating levels. The applicator must be tuned to produce and maintain the desired microwave mode, concentrating the electric field strength in the propellant flow and away from the walls.

The study reported here was conducted with a resonant cavity as the microwave applicator. Previous research has shown that over 97 percent of the incident microwave power may be consistently coupled or absorbed into plasmas in this type of applicator, over a wide range of operating conditions. ${ }^{1,2}$ Furthermore, microwave discharges have been demonstrated in a variety of gases, ${ }^{5}$ including $\mathrm{He}, \mathrm{N}_{2}, \mathrm{H}_{2}$, and $\mathrm{NH}_{3}$, and have been maintained to pressures greater than $300 \mathrm{kPa}$. Maximum CW power levels to $2.5 \mathrm{~kW}$ have been investigated for MET applications. Active flow stabilization devices, such as an axial bluff body, have been shown $2,4,5$ to influence the location and behavior of microwave plasmas.

The two available industrial heating bands at 915 and $2450 \mathrm{MHz}$ are both feasible microwave frequencies at which to operate the MET. Prior research has concentrated on the higher frequency. Static plasma formation in $\mathrm{H}_{2}$ was studied by Arata, et al., ${ }^{6}$ at the lower frequency, but not for thruster applications. The present work was conducted at $915 \mathrm{MHz}$ because the longer wavelength at this frequency permits larger cavity and plasma dimensions for more convenient fabrication and observation, and also because high power generators are more cost effective and more efficient at the lower frequency. The generator employed for the present testing allows $\mathrm{CW}$ power levels up to $30 \mathrm{~kW}$ to be applied to the microwave cavity, a level sufficient to evaluate the MET for primary propulsion applications.

A potential advantage of the MET over other electrothermal thrusters, such as arcjets and resistojets, is that there are no electrodes or heating elements in contact with the plasma or the heated propellant. Thus the erosion of these structures due to energy dissipative interactions at their surfaces is eliminated, along with the concomitant thruster performance and lifetime degradation. A further advantage provided in the MET lies in the ability to externally optimize, within limits, the location, volume, and shape of the plasma within the discharge tube. These considerations may ultimately enable the MET to achieve near theoretical levels of performance ${ }^{7}$ for an electrothermal thruster.

The preliminary testing performed in this study characterized plasma starting conditions in helium $(\mathrm{He})$, nitrogen $\left(\mathrm{N}_{2}\right)$, and hydrogen $\left(\mathrm{H}_{2}\right)$ and investigated the conditions under which symmetric, axial "spike" plasmas formed and unformed in the flowing gases. Plasma operation at elevated power levels also was evaluated, and the effect of a strong magnetic field in producing magnetic nozzle effects on $\mathrm{He}$ plasmas was documented. The testing was conducted in an open channel configuration which did not allow thruster performance measurements to be made. The test apparatus also was limited to discharge chamber pressures below atmospheric.

\section{Theory}

This section is divided into two parts. The first part describes the electrical properties of an ideal cylindrical cavity operating in transverse magnetic (TM) resonant modes. The second part treats the high-frequency induced breakdown of a gas.

\section{$\underline{T M}_{01 p}$ Resonant Cavity Theory}

A conducting enclosure which has the geometry of a right circular cylinder can act as a cavity resonator under appropriate conditions. Only the $\mathrm{TM}_{01 \mathrm{p}}$ resonant modes (with $\mathrm{p}=1$ or 2 ) are treated in this discussion. The field equations which describe these modes are: ${ }^{8}$

$$
\begin{gathered}
\mathbf{E}_{\mathbf{z}}=E_{01 \mathrm{p}} \mathbf{J}_{\mathbf{0}}\left(\frac{\chi_{01} \rho}{a}\right) \cos \left(\frac{\mathrm{p} \pi z}{h}\right) \\
\mathbf{E}_{\phi}=0
\end{gathered}
$$




$$
\begin{gathered}
\mathbf{E}_{\rho}=E_{01 p} \frac{\mathrm{p} \pi a}{\chi_{01} h} \mathbf{J}_{1}\left(\frac{\chi_{01} \rho}{a}\right) \sin \left(\frac{\mathrm{p} \pi z}{h}\right) \\
\mathbf{H}_{\mathbf{z}}=0 \\
\mathbf{H}_{\phi}=E_{01 p} \frac{j \omega \varepsilon a}{\chi_{01}} \mathbf{J}_{1}\left(\frac{\chi_{01} \rho}{a}\right) \cos \left(\frac{\mathrm{p} \pi z}{h}\right) \\
\mathbf{H}_{\rho}=0
\end{gathered}
$$

The resonant frequency for excitation of the $\mathrm{TM}_{01 \mathrm{p}}$ modes may be related to the radius and length of the cavity (through a derivation from the above equations) by

$$
\left(f_{r}\right)_{01 \mathrm{p}}^{T M}=\frac{\mathrm{v}_{\mathrm{p}}}{2 \pi} \sqrt{\left(\frac{\chi_{01}}{a}\right)^{2}+\left(\frac{\mathrm{p} \pi}{h}\right)^{2}}
$$

in which the phase velocity, $v_{p}$, of the microwave radiation in the cavity medium appears. This phase velocity is given by $1 /(\mu \varepsilon)^{3 / 2}$. For free space, $v_{p}$ equals the speed of light in vacuum, i.e.,

$$
\mathrm{v}_{\mathrm{p}}=\frac{1}{\sqrt{\mu_{0} \varepsilon_{0}}}=\mathrm{c} \approx 2.998 \times 10^{8} \mathrm{~m} / \mathrm{sec}
$$

For an electromagnetic wave propagating in a lossless dielectric medium, in which $\varepsilon>\varepsilon_{0}$, the velocity of propagation will be less than $\mathrm{c}$.

For a given frequency and propagation medium, the relationship between the radius and length of the cavity. at resonance is fixed by Eq. (7). This relationship is plotted in Fig. 1 for a frequency of $915 \mathrm{MHz}$. One curve is for wave propagation in free space. The other is for a cavity filled with a lossless dielectric material of $\varepsilon \approx 1.15 \varepsilon_{0}$, which reduces the propagation velocity to $2.8 \times 10^{8} \mathrm{~m} / \mathrm{sec}$. The figure shows that a cavity with a large radius has a shorter resonant length and that small changes in the radius result in small changes in the resonant length.

A primary parameter of interest in a plasma production device is the electric power density, $P$, which is proportional to $|\mathbf{E}|^{2}$. Thus

$$
P \propto \mathbf{E}_{\rho}^{2}+\mathbf{E}_{\phi}^{2}+\mathbf{E}_{z}^{2}
$$

A plasma forms in regions where $P$ is a maximum. From Eq. (2), the electric power density in $\mathrm{TM}_{01 \mathrm{p}}$ modes is dependent upon $\mathbf{E}_{\mathrm{p}}{ }^{2}$ and $\mathbf{E}_{\mathrm{z}}{ }^{2}$ only.
Contour plots of the electric power density for the $\mathrm{TM}_{011}$ and $\mathrm{TM}_{012}$ resonant modes are shown in Figs. 2(a) and (b). The value taken for the cavity radius is that of the experimental cavity described in the following section. The plots have been generated for a resonant frequency of $915 \mathrm{MHz}$. Note that each contour represents the electric power density on a cutting plane containing the cavity axis. Because the electric fields of the $\mathrm{TM}_{01 \mathrm{p}}$ modes do not have an azimuthal dependence, all such cutting planes are identical.

The $\mathrm{TM}_{011}$ mode is characterized by two axial locations of maximum electric power density, one at $z=0$ and the other at $z=h$, and an axial minimum at $z=h / 2$. It is also characterized by an annular region of high electric field density at $z=h / 2$; in this region the electric power density achieves a maximum intensity at $\rho / a=0.748$ as a consequence of the $\mathrm{J}_{1}\left(\chi_{01} \rho / a\right)$ term in the $\mathbf{E}_{\mathrm{\rho}}$ component. The electric power density pattern for the $\mathrm{TM}_{012}$ mode seen in Fig. 2(b) is simply that of the $\mathrm{TM}_{011}$ mode in Fig. 2(a) replicated back-to-back on the cavity axis.

A resonant cavity containing a plasma can be considered as a load on the end of a power transmission line. In the cavity MET used in this investigation, microwave power from the TEM mode of a coaxial transmission line is coupled into the cavity via a linear probe oriented perpendicular to the cavity axis and located at the wall maxima of the $\mathrm{TM}_{01 \mathrm{p}}$ mode electric field patterns. Collin ${ }^{9}$ and Frasch ${ }^{10}$ have shown that by properly adjusting the probe insertion distance into the cavity and properly positioning the cavity shorting flange, the complex impedance of the plasma/cavity system can be exactly matched to that of the microwave circuit supplying the power. When correct matching is achieved, essentially all the incident power is coupled into the plasma. Reflection losses are miniscule and losses from external tuning devices are eliminated.

\section{Breakdown and Plasma Behavior in an AC Field}

Under proper conditions, the high frequency electric fields contained within a resonant cavity will cause breakdown in a gas present, creating a highly conductive plasma. This in turn continues to absorb power from the standing fields. The plasma dissipates the absorbed energy thermally, radiantly, and through internal excitation.

The primary mechanism by which a gas absorbs energy from an AC field is through the acceleration of free electrons present and their subsequent collisions with gas molecules. These electrons collide with and either directly ionize the atomic and molecular species (heavy particles) present or excite them to elevated energy levels. The energy gained by an electron between collisions varies directly with the electric field strength and with the mean free path. The latter is inversely proportional to the heavy particle number density and hence to the pressure $p$. Thus the ratio $E / p$ is a 
measure of the average energy gained by the accelerated electrons between collisions. Significant ionization results when $E / p$ is large enough that a sufficient electron-heavy particle collision frequency and sufficient energy deposition per collision both occur. This ionization produces additional electrons to be accelerated. When the ionization rate is high enough that the production rate of electrons exceeds their loss rate (due to diffusion, ion-electron recombination, etc.), a cascade or avalanche breakdown occurs.

In an $\mathrm{AC}$ electric field at microwave frequencies, the field direction reverses before more than a few of the free electrons present can be accelerated to reach a solid structure. The electrons thus continue oscillating as they undergo collisions with the heavy particles present, maintaining plasma ionization. No participation by or interaction with electrodes or walls is required in this process.

The conductivity of a gas is defined as the ratio between current density and the applied field and is given by: ${ }^{11}$

$$
\sigma=\frac{n_{e} q^{2}}{m_{e}\left(v_{m}+j \omega\right)}
$$

From this, the field-supplied power density of the breakdown discharge can be determined by the field equivalent of $P=I V$. Thus:

$$
P=\frac{n_{e} q^{2}}{m_{e}\left(v_{m}+j \omega\right)} E_{0}^{2} e^{2 j \omega t}
$$

Therefore the plasma acts as an ohmic heating source with the power absorbed by the plasma proportional to the square of the electric field, i.e., to the electric power density. Since the plasma conductivity is complex, the load impedance of the cavity due to the plasma will be complex.

A plasma discharge will be maintained when the production of new ions exceeds the rate of their loss by all ion removal processes. In practice, this requires that for a plasma to persist, the ratio $E / p$ must be sufficient to maintain substantial ion production. This value of $E / p$ will be less than that required to start the plasma.

\section{$\underline{\text { Experimental }}$}

The experimental apparatus used in this investigation has been described in detail in Refs. 7 and 12. The microwave components consist of a generator, a power delivery circuit, the cavity, and tuning mechanisms. The propellant gas system includes a gas feed system, injector assembly, discharge tube, and evacuation system. Completing the apparatus is a high field electromagnet, with which magnetic nozzle effects were investigated.

\section{$\underline{\text { Microwave Circuit }}$}

The microwave generator is a magnetron-tube, industrial heating unit modified to produce a low ripple, $915 \mathrm{MHz}$ output signal at power levels up to $30 \mathrm{~kW}$. The peak-topeak ripple of the signal ranges from 1.8 to 2.7 percent of the DC value over the upper half of the power range. The magnetron tube is protected from reflected power by a 3 -port circulator and water load in the generator.

The power delivery circuit is shown in Fig. 3. Most of the circuit is fabricated of WR975 rectangular waveguide. The power line to the cavity is $12.7 \mathrm{~cm}$ (5 in.) diameter flexible coaxial line. The phase shifter-tuner receives the full output signal from the generator through a 3-port circulator. Via double bucket shorting assemblies manipulated by two control cranks, any desired fraction from 0 to 99 percent of the input signal may be reflected back into the 3-port circulator and thence to the cavity. The unreflected microwave power passes through the output port and is absorbed in the ballast water load. The phase shifter-tuner allows the applied power to be continuously and smoothly adjusted from low levels of perhaps $250 \mathrm{~W}$, suitable for starting the discharge at low pressure, to operating levels near the generator maximum, while the generator magnetron tube output is maintained constant.

Reflected power from the phase shifter-tuner, after being diverted into the upward leg of the 3-port circulator (seen in Fig. 3), passes through a dual directional coupler and then through a waveguide-coaxial line transition into the $5 \mathrm{~m}$ long flexible coaxial line leading to the power input port of the cavity. The forward power to and reflected power from the cavity are read from thermistor power sensors on the $60 \mathrm{~dB}$ couplers of the dual directional coupler.

The microwave cavity is shown in Fig. 4. All its interior surfaces are silver-plated to minimize surface current losses and reflect incident radiant energy from the discharge tube. The cavity is a cylinder $45.7 \mathrm{~cm}$ in i.d. by $57.2 \mathrm{~cm}$ long, having a fixed downstream end flange and a movable upstream shorting flange. Both flanges have on-axis holes and collar pieces closely fitting the discharge tube which passes through them. The shorting flange may be translated by a crank and gearing mechanism to achieve cavity interior lengths from 16.5 to $40.6 \mathrm{~cm}$. From Eq. (7), this covers the predicted 19.6 and $39.2 \mathrm{~cm}$ resonant lengths of the $\mathrm{TM}_{011}$ and $\mathrm{TM}_{012}$ modes, respectively.

The power input port of the cavity, prominently seen in Fig. 4, is perpendicular to the cavity axis and is centered $9.8 \mathrm{~cm}$ from the interior front flange surface, at the expected wall maxima of the electric power density in both the $\mathrm{TM}_{011}$ and $\mathrm{TM}_{012}$ modes. Placement of the port here facilitates coupling the input power from the coaxial input port to the TM cavity modes. The inner conductor probe of 
the input port has a hemispherical end, and its insertion depth into the cavity is adjustable from 0.85 to $4.45 \mathrm{~cm}$.

The cavity viewport is located under the power input probe. All external surfaces of the cavity, including the shorting flange and the power input port, are equipped with water cooling loops to dissipate heat originating from the plasma discharge. In addition, a high flow of nitrogen gas into the power input port provides cooling for the discharge tube.

\section{Propellant Gas System}

Helium, nitrogen, and hydrogen were tested as the propellant gases in these experiments. All are a minimum 99.99 percent pure. The propellant gas feed to the discharge tube is regulated by a mass flow controller, which provides maximum flowrates of 83,47 , and $60 \mathrm{slpm}$ for the $\mathrm{He}, \mathrm{N}_{2}$, and $\mathrm{H}_{2}$ propellants, respectively.

The configuration of the injector, discharge tube, and evacuation system within the cavity and magnet is shown in Fig. 5. The head of the injector assembly is shown in Fig. 6. Gas entry into the discharge tube is via the two outer, curved tubulations. These are designed to inject the propellant gas with large angular momentum and minimum axial momentum in order to stabilize the plasmas forming downstream in the discharge tube. The central axial hole of the injector head connects to a Bourdon mechanical pressure gauge for monitoring the discharge tube pressure. The injector assembly is vacuum sealed into the upstream end of the discharge tube, but the seal cannot be pressurized. Hence, the discharge tube pressure had to be maintained below atmospheric and was in fact limited to $69 \mathrm{kPa}$ (10 psia).

The discharge tube is fabricated of fused quartz for maximum optical transparency and low dielectric loss. The tube, which has an i.d. of $50 \mathrm{~mm}$ and a wall thickness of $2.5 \mathrm{~mm}$, extends the entire length of the cavity and is sealed into a downstream end fixture of the same i.d. as the tube. This end fixture, made of high purity copper, extends through and is conductively heat sunk to the bore liner of the magnet, as shown in Fig. 5. From it, the heated propellant gas is exhausted into a port volume, which is evacuated either to a $3.0 \mathrm{~m}$ diameter by $5.8 \mathrm{~m}$ long vacuum tank through a $30 \mathrm{~cm}$ diameter gate valve, indicated in the figure, or by a side pumping line to a mechanical pump. Most of the testing reported was performed with the latter arrangement, because the pumping rate could thereby be throttled, allowing the discharge tube pressure to be varied independently of the propellant flowrate. A transducer on the port pumpout line (upstream of the throttling valve) was used to read low discharge tube pressures. Evacuation through the gate valve into the tank produced discharge tube pressures on the order of $10 \mathrm{~Pa}$, regardless of the propellant flowrate.
Such pumping was only employed for investigating magnetic nozzle effects at low pressure.

\section{Magnet}

A short solenoidal superconducting magnet having an effective i.d. of about $10.6 \mathrm{~cm}$ was employed for testing magnetic nozzle effects. The superconducting magnet produces a maximum on-axis magnetic field strength of $5.75 \mathrm{~T}$ at a magnet current of $117 \mathrm{~A}$. The magnet current and field strength may be operated at any levels up to these maximum values. The magnet is mounted adjoining the downstream end flange of the microwave cavity, as seen in Fig. 5, with the bore axis congruent with the cavity axis and the discharge tube end fixture mounted inside the watercooled magnet bore liner. The bore liner has a thermal capacity of more than $25 \mathrm{~kW}$, enabling it to absorb and dissipate essentially all of the thermal energy added to the propellant gas in the discharge tube.

\section{$\underline{\text { Results }}$}

\section{$\underline{\text { Plasma Starting Conditions }}$}

A series of experiments was conducted to determine the conditions for breakdown and plasma formation in both the $\mathrm{TM}_{011}$ and $\mathrm{TM}_{012}$ modes for each of the three propellant gases. Two different methods were employed to obtain these conditions. In the first, the incident power was set at a fixed level and the discharge tube pressure was slowly reduced, with essentially no gas flow. In the second method, the pressure was held constant and the applied microwave power was slowly increased, again under essentially no flow conditions. In both methods the ratio $E / p$ was increased until the starting conditions were achieved. In all tests the cavity shorting flange was positioned at the theoretical distances given by Eq. (7) for the two modes. Figures 7(a) to (c) show the data obtained.

The plots in Fig. 7 indicate that breakdown is achieved at lower values of $E / p$ in the $\mathrm{TM}_{012}$ mode than in the $\mathrm{TM}_{011}$ mode for all the gases. In the $\mathrm{TM}_{012}$ mode, breakdown always occurred at the central axial node of the electric field. In the $\mathrm{TM}_{011}$ mode, breakdown occurred at either of the identical upstream and downstream axial nodes of the field, located at the cavity endwalls. By comparing Figs. 2(a) and (b), it can be seen that the central node of the $\mathrm{TM}_{012}$ mode is twice as large as either $\mathrm{TM}_{011}$ node. The substantially greater volume of gas and number of free electrons interacting with the electric field in the $\mathrm{TM}_{012}$ node explains the greater ease of starting observed in this mode.

From Figs. 7(a) to (c) it may also be noted that reduced breakdown values of $E / p$ were observed in the $\mathrm{TM}_{012}$ mode when the power input probe was retracted from the full-in 
insertion of $4.45 \mathrm{~cm}$ to the arbitrary value of $3.18 \mathrm{~cm}$. The fact that the probe insertion perturbs the field pattern of the mode may explain this result, assuming that breakdown is more readily achieved as the magnitude of the perturbation is reduced. Retracting the power input probe had a similar effect in facilitating plasma formation in the $\mathrm{TM}_{011}$ mode.

The minimum power levels and corresponding pressures at which breakdown was achieved were $17 \mathrm{~W} @ 405 \mathrm{~Pa}$ for $\mathrm{He}, 150 \mathrm{~W} @ 315 \mathrm{~Pa}$ for $\mathrm{H}_{2}$, and $175 \mathrm{~W} @ 115 \mathrm{~Pa}$ for $\mathrm{N}_{2}$. Above and below these pressures, the power required for breakdown increased. By comparison of the plots in Fig. 7 it may be seen that the breakdown pressure in $\mathrm{He}$ at a given applied power level is more than an order of magnitude higher than that for $\mathrm{H}_{2}$ or $\mathrm{N}_{2}$. An explanation for these trends lies in the differences between the monatomic gas $\mathrm{He}$ and the two diatomic gases. The diatomic gases have many more internal energy levels (vibrational and rotational) than do the monatomic gas. These internal energy levels dissipate much of the energy absorbed from electron collisions without increasing the molecular electronic energy, and hence their excitation does not substantially assist ionization. This factor outweighs the importance of the actual ionization potentials of the neutral gas molecules, which are 24.6, 15.4 , and $15.6 \mathrm{~V}$ for $\mathrm{He}, \mathrm{H}_{2}$, and $\mathrm{N}_{2}$, respectively. Hence the breakdown of diatomic gases characteristically requires considerably increased values of $E / p$, as observed.

Each data point shown in Figs. 7(a) to (c) is an average from at least two starts in which the measured variable differed from the average value by less than 15 percent. All of the plasma starting data were taken at ambient conditions, with at least $6 \mathrm{~min}$ of purging at moderate flowrate with the gas under investigation between successive starting attempts. The purging was necessary to achieve reproducibility in the starting condition data. If a repeat start was attempted without adequate prior cooldown and purging, it was found that the start was achieved much more readily, i.e., at a considerably lower value of $E / p$. This was apparently the result of the discharge tube wall temperature still being somewhat above room temperature, due to heating from the preceding plasma operation. The sensitivity of the starting conditions to the wall temperature may indicate the residual presence of temperature-sensitive wall conditions which promote free electron production.

\section{Spike Plasma Formation and Operating Envelope}

After a plasma is started at low pressure, low flowrate, and modest applied microwave power, the levels of all these operating variables must be substantially raised for the plasma to be useful as the heating mechanism in an electrothermal thruster. On doing so in the tests performed for this study, a consistent behavior was observed with all the propellant gases and in both cavity modes tested. As the pressure was increased above a few $\mathrm{kPa}$, the diffuse low pressure plasma would coalesce into a more intense, axially unsymmetric plasma in the node at which it formed. This unsymmetric plasma was generally observed to be U-shaped, as illustrated in Fig. 8(a), with both ends attached to the discharge tube wall and the plasma apparently following the electric field lines of the tuned mode. The plasma normally (but not always) attached to the top side of the horizontal discharge tube, suggesting that buoyancy effects on the plasma are important in determining its equilibrium unsymmetric orientation.

The unsymmetric plasma described severely constrains the maximum absorbed power, due to local heating of the discharge chamber wall at the points of attachment. This type plasma also has the deficiency of nonuniformly heating the propellant gas flow. Early in the testing it was discovered that the fixed U-shaped plasma was caused to rotate around the discharge tube by increasing the propellant flowrate. This was found due to the vorticity, or angular momentum, introduced into the gas flow by the injector head (Fig. 6), which was designed to maximize the angular to axial momentum of the inflowing gas. The plasma rotation was always in the same direction as the gas flow vorticity. The discharge plasma was observed to behave as a connected, semi-rigid volume resisting flow of the incoming gas through it. Above the onset flowrate necessary for initiating plasma rotation, the rotational frequency increased monotonically with increasing flowrate. During rotation, the apparent shape, volume, and attachment spots of the plasma changed little in appearance.

At some point as the propellant flowrate and plasma rotational rates were increased further, the plasma nearly always detached from the discharge tube wall to form an axially-symmetric, elongated, still-rotating plasma situated on or close to the tube axis. Because of its appearance, this type of plasma is subsequently referred to as a spike plasma. It is depicted in Fig. 8(b). In some cases, the spike plasma formed almost directly from the stationary unsymmetric plasma on increasing the flowrate, with hardly any rotation first.

The spike plasma formation mitigates many of the problems associated with utilizing a plasma discharge in a cylindrical tube for electrothermal heating of a propellant gas. The plasma is maximally separated from the discharge tube wall, thus minimizing conductive heating of the wall. Further, the propellant gas flowing around, along, and through the plasma is axisymmetrically heated. The spike plasma thus is well suited as the heating mechanism in a high power, high flowrate MET.

Because of the potential importance of the spike plasmas, the conditions for their formation and unformation were investigated. The latter process leads to reforming a wallattached plasma. The data from all the testing performed on $\mathrm{He}$ and $\mathrm{N}_{2}$ are presented in Figs. 9 and 10. The incomplete data obtained for spike plasma formation and unformation 
in $\mathrm{H}_{2}$ agreed with the low pressure data shown for $\mathrm{He}$ in Fig. 9. In the figures the propellant flowrate at which the spike plasma formed or unformed is plotted as a function of the pressure. These two variables could be independently controlled over considerable ranges by means of the throttling valve on the port pumpout line. The applied microwave power is indicated for the data points.

Though Figs. 9 and 10 show much scatter in the data for both spike plasma formation and unformation, important trends are quite clear. These are indicated by the formation and unformation trend lines on the figures. The mass flowrate necessary to cause the plasmas to "spike" increases with pressure. This effect apparently reflects an increase with pressure in the dissipation of the flow vorticity introduced into the inflowing gas by the injector head. (The injector head was in all cases located at least $17 \mathrm{~cm}$ upstream of the upstream end of the plasma being rotated.) Comparison of the figures quantifies the observation that $\mathrm{N}_{2}$ plasmas spike at much lower pressures and mass flowrates than do $\mathrm{He}\left(\right.$ or $\mathrm{H}_{2}$ ) plasmas. The $\mathrm{N}_{2}$ spike plasmas also demonstrated considerably more hysteresis between their conditions of formation and unformation than did the $\mathrm{He}$ plasmas.

The applied (or absorbed) microwave power in the plasma does not appear to have a first order effect on the conditions at which the plasma either spikes or unspikes. At higher pressures, more applied power is normally required to maintain a stable plasma, in either an unsymmetric or a spike condition. This accounts for the general increase noted in Figs. 9 and 10 in the power associated with the data points at the higher pressure levels.

For both $\mathrm{N}_{2}$ and $\mathrm{He}$, spike plasma formation in the $\mathrm{TM}_{011}$ mode is similar to that in the $\mathrm{TM}_{012}$ mode but occurs at substantially higher mass flowrates and pressures. This is evidently due to the relative strengths of attachment of the unsymmetrical plasmas to the wall before spike plasma formation. In the $\mathrm{TM}_{012}$ mode the wall-attached plasma, located at the central cavity node, has no nearby ground plane or structure on which its guiding electric field lines may seat. In the $\mathrm{TM}_{011}$ mode, whether the plasma is in the upstream or downstream node, the guiding electric field lines seat to the endwall collar piece just outside the discharge tube. Such seating had the apparent effect of resisting the rotation of the plasma attachment point by the vorticity of the inflowing propellant gas, requiring higher flowrates to achieve formation of a spike plasma.

One factor which contributed substantially to the scatter seen in the data points of Figs. 9 and 10 was the normal occurrence of plasma fluctuations or instabilities in the transition both to and from a spike plasma. Just before an unsymmetric plasma spiked, it typically demonstrated considerable buffeting of its upstream end by the propellant gas flow. Just before unspiking, the plasmas generally underwent major instabilities in shape, location, or rotation. In all cases the fluctuations and instabilities appeared to be due to gas dynamic forces acting on the plasma volume. These gas dynamic forces depend in a complicated way on the pressure, mass flowrate, effective flow vorticity, and flow turbulence, and also on the plasma shape, volume, location, and rotation. Also contributing to the scatter in the data points were the varying and uncontrolled thermal conditions of the discharge tube wall in the plasma region. Local plasma attachment to the tube wall can create a hot spot on the wall which tends to resist rotation of the plasma attached to it.

\section{Higher Power Operation}

Table I presents the maximum power conditions tested for the three propellants. All the data were taken with the plasmas in the spike condition. Indeed it was impossible to maintain operation of unspiked plasmas of any of the gases at more than a fraction of the power levels indicated in the table, for reasons cited in the preceding section.

The microwave power coupling efficiencies given in the table are the ratio of the applied minus the reflected power to the applied power. All the coupling efficiencies given for the maximum power conditions were measured with the power input probe fully inserted into the cavity. This was found to give the maximum coupling efficiency for all plasmas at applied power levels greater than about $2 \mathrm{~kW}$. Below this power level, optimum tuning of the plasmas was achieved at probe insertion distances less than the maximum $(4.45 \mathrm{~cm})$, and plasmas of all the tested gases in both modes could be tuned for coupling efficiencies greater than 90 percent. A longer power input probe is expected to improve the coupling efficiencies under high power conditions. From Table I, the lowest efficiency was observed under the highest applied power condition (that for $\mathrm{N}_{2}$ ). All these results are consistent with predictions and observations ${ }^{10}$ that as the power absorbed in the plasma increases, the impedance of the loaded cavity increases, requiring further insertion of the power input probe for exact impedance matching.

The factors that limited the high power testing in this investigation are of interest. For $\mathrm{He}$, the limiting factor was a hot spot which developed on the discharge tube wall where the downstream tail of the spike plasma deflected from the axis towards the power input probe. This phenomenom was not observed with the spike plasmas in the other two gases. The high maximum power level achieved with $\mathrm{N}_{2}$ reflects the efficient internal energy absorption mechanisms (primarily from the excitation of rotational and vibrational states) provided by the molecular species present. These substantially reduce the plasma temperature for a given level of power absorption. 
The limiting factor in the high power $\mathrm{H}_{2}$ plasmas was the intense heating of the surrounding discharge tube wall by the plasmas. This phenomenon is likely due to the thirdbody recombination of atomic hydrogen at the wall. Such recombination releases approximately $52 \mathrm{kcal} / \mathrm{mole}\left(\mathrm{H}_{2}\right)$ of heat there. The heating was sufficiently intense under the high power conditions of Table I to soften and devitrify the fused quartz discharge tube in the region of the plasma, indicating that wall temperatures of approximately $1950 \mathrm{~K}$ were reached. In addition, the reaction and heating at the wall volatilized a high temperature product which deposited on the wall just downstream of the plasma location. The interference patterns of the deposited coating indicated that the deposition was controlled by the thermal profile along the wall surface. The coating was also observed to be heated to very high temperatures (in fact, white hot), causing the softened and devitrified area of the quartz tube wall, as well as the region of the deposit, slowly to extend downstream. The intense heating of the deposited coating indicates an elevated dielectric loss tangent and concomitant microwave power absorption, because the heating persisted even with the plasma discharge extinguished.

\section{Magnetic Nozzle Effects}

Preliminary tests were conducted to assess magnetic nozzle effects of the superconducting magnet on plasmas maintained in the microwave cavity. The objective was to evaluate whether a strong solenoidal magnetic field offers significant advantages in realizing the MET as a high performance thruster. These potential advantages lie in (1) constricting the plasma in the throat/nozzle region to reduce wall heating and to increase recombination of plasma species and (2) stabilizing and controlling the plasma in the cavity for optimal performance in heating the propellant gas.

Magnetic field tests were carried out on He plasmas in both the $\mathrm{TM}_{011}$ and $\mathrm{TM}_{012}$ modes. Failure of the magnet power supply prevented tests with $\mathrm{N}_{2}$ and $\mathrm{H}_{2}$ plasmas. The magnet current during the $\mathrm{He}$ testing was varied over the range of 0 to $80 \mathrm{~A}$, giving maximum on-axis field strengths up to $3.9 \mathrm{~T}$. The corresponding magnetic pressure on the plasma at this field strength is $6.0 \times 10^{6} \mathrm{~Pa}$. The discharge tube was either evacuated through the gate valve, giving constant low pressures of about $10 \mathrm{~Pa}$, or via the throttled port pumpout line, giving higher pressures to $44 \mathrm{kPa}$.

At the low pressures maintained with the gate valve open, the magnetic field was observed to have a major magnetic nozzle effect on the He plasmas. Figures 11(a) and (b) show photographs of a $\mathrm{TM}_{011}$ mode He plasma with no magnet current and at the maximum 80 A magnet current tested, respectively. The plasma may be seen passing through the downstream cavity end flange into the magnet bore. The flowrate was about $4.5 \mathrm{slpm}$, the absorbed power about $82 \mathrm{~W}$, and the pressure about $10 \mathrm{~Pa}$ when the Fig. 11(b) photograph was taken. Without the magnetic field present, the plasma essentially fills the discharge tube, as shown in Fig. 11(a). With the magnetic field, the plasma column diameter inside the magnet was constricted to about 15 to 20 percent of the tube inner diameter. The plasma constriction lessened with increasing distance from the magnet but was still significant as much as $25 \mathrm{~cm}$ upstream of the magnet, inside the discharge tube and cavity. Through a viewport in the vacuum tank, opposite the magnet bore, it was also observed that the magnetic field drew the plasma through the bore and as far as $1 \mathrm{~m}$ into the tank, brightly illuminating the downstream side of the gate valve housing.

At higher discharge tube pressures, the magnetic nozzle effect was considerably reduced. At $6.5 \mathrm{kPa}$, with the gate valve closed and throttled pumping through the port pumpout line, the plasma column diameter of a $\mathrm{TM}_{012}$ mode plasma was reduced to about 50 percent of its normal diameter by application of the $80 \mathrm{~A}$ field. At pressures above this, up to the $44 \mathrm{kPa}$ maximum tested, the observed magnetic nozzle constriction of the plasmas was essentially confined to the magnet bore volume itself, with the plasma apparently drawn into the bore volume and progressively constricted to a substantially smaller diameter. This produced a conical appearance of the plasma as it entered the bore volume. Full evaluation of the benefits of a magnetic nozzle with the MET awaits higher pressure testing with a throat-nozzle assembly installed in the magnet bore.

\section{Conclusions}

Starting conditions of pressure and applied microwave power were characterized for $\mathrm{He}, \mathrm{N}_{2}$, and $\mathrm{H}_{2}$ plasmas in the $\mathrm{TM}_{011}$ and $\mathrm{TM}_{012}$ modes, with essentially no gas flow. These conditions were found to be quite reproducible and independent of whether the plasma was started by reducing the pressure at constant power or increasing the power at constant pressure. The $\mathrm{He}$ plasmas formed much more readily than either the $\mathrm{N}_{2}$ or the $\mathrm{H}_{2}$ plasmas, and the $\mathrm{TM}_{012}$ mode plasmas formed at lower power levels than the corresponding $\mathrm{TM}_{011}$ mode plasmas, as expected. Minimum applied power conditions found for plasma formation were $17 \mathrm{~W}$ for $\mathrm{He}, 175 \mathrm{~W}$ for $\mathrm{N}_{2}$, and $150 \mathrm{~W}$ for $\mathrm{H}_{2}$, all in the $\mathrm{TM}_{012}$ mode.

An important result from this preliminary investigation was the discovery of spike plasma formation in all the propellant gases tested and in both the $\mathrm{TM}_{011}$ and $\mathrm{TM}_{012}$ modes. These plasmas are stable, free-floating, fixed in location, rapidly rotating, and situated on or close to the axis of the cylindrical discharge tube. They are formed by injecting the propellant flow with maximum vorticity, giving a high ratio of angular to axial momentum in the gas, and then sufficiently increasing the inflow rate. Spike plasma formation from the unsymmetrical plasmas present at lower propellant flowrates is attributed to fluid dynamic forces of the vortical flow acting on the plasma volume. In this 
interaction the plasma behaves as a semi-rigid body resistant to flow through it.

The spike plasma is of critical importance in developing a successful MET because it minimizes the plasma/wall interaction, maximizes propellant gas heating, overcomes static plasma asymmetry and wall attachment, and maximizes the power that may safely be absorbed in the plasma. This type plasma also permits direct control of the plasma volume when the absorbed power is increased, by correspondingly increasing the pressure.

Conditions of pressure, mass flowrate, and applied power under which the plasmas spiked and unspiked were investigated. For all of the plasmas the flowrate at which spiking occurred increased with the pressure and was greater for $\mathrm{TM}_{011}$ mode plasmas than for $\mathrm{TM}_{012}$ plasmas. These trends were also true of the conditions for unspiking. The plasma power level did not have a first order effect on the spiking or unspiking conditions. $\mathrm{N}_{2}$ plasmas were found to spike at much lower values of flowrate and pressure than either $\mathrm{He}$ or $\mathrm{H}_{2}$ plasmas and to remain spiked over a much larger relative decrease in flowrate or increase in pressure from the spiking conditions. The spiking and unspiking plasma transitions are both associated with plasma fluid instabilities. This is believed largely responsible for the poor reproducibility observed in the conditions at which the transitions occurred.

Applied microwave power levels to 3.5, 11.2, and $4.2 \mathrm{~kW}$ were tested in $\mathrm{He}, \mathrm{N}_{2}$, and $\mathrm{H}_{2}$ plasmas, respectively, with all the plasmas in the spike condition. Power coupling efficiencies ranged from 54 to 86 percent under the maximum power conditions. These coupling efficiencies were limited by the maximum insertion of the power input probe into the cavity. With a longer probe, improved coupling efficiencies are expected. The factor limiting the power which could be applied to the $\mathrm{H}_{2}$ plasmas was the intense general heating of the adjacent discharge tube wall, believed due to atomic hydrogen recombination at the wall. From the observed softening and volatilization of the fused quartz wall, temperatures there of about $1950 \mathrm{~K}$ are indicated to have occurred.

Magnetic nozzle effects on He plasmas were investigated at magnetic field strengths to $3.9 \mathrm{~T}$, created in the solenoidal superconducting magnet attached to the downstream flange of the microwave cavity. At low pressures of about $10 \mathrm{~Pa}$, magnetic nozzle effects were very prominent, causing constriction of the plasma to a small fraction of its diameter without the field present, strongly drawing the plasma through the magnet bore, and influencing the plasma over distances of tens of centimeters upstream and downstream of the magnet. At higher pressures above about $10 \mathrm{kPa}$, the apparent magnetic nozzle effects on the plasma were much diminished but still evident, being limited largely to the magnet bore volume. The highest pressure investigated was $44 \mathrm{kPa}$.

The low pressure, open channel testing reported in this paper supports optimism regarding the feasibility and performance of the MET as an advanced electrothermal thruster. The spike plasma formation observed enables operation at maximum absorbed power levels with optimal propellant heating. For use with $\mathrm{H}_{2}$ propellant, the testing indicates the need for a discharge tube fabricated of a material with higher temperature capability than quartz. The effectiveness of a magnetic nozzle has been demonstrated at low pressures and remains to be evaluated with a throatnozzle assembly at the above-atmospheric pressures anticipated for optimum MET operation.

\section{Acknowledgment}

The authors wish to gratefully acknowledge the expert assistance and enthusiasm of the late William E. Parkinson in assembling, testing, and maintaining the apparatus with which the investigation here reported was performed.

\section{$\underline{\text { References }}$}

1. Hawley, M. C., Asmussen, J., Filpus, J. W., Whitehair, S., Hoekstra, C., Morin, T. J., and Chapman, R., "Review of Research and Development on the Microwave Electrothermal Thruster," Journal of Propulsion and Power, Vol. 5, Nov.-Dec. 1989, pp. 703-712.

2. Balaam, T. and Micci, M., "Investigation of FreeFloating Nitrogen and Helium Plasmas Generated in a Microwave Resonant Cavity," AIAA Paper 89-2380, July 1989.

3. Whitehair, S. and Asmussen, J., "Experiments and Analysis of a Compact Microwave Electrothermal Thruster," DGLRAIAA/JSASS 20th International Electric Propulsion Conference, IEPC Paper 88-101, Oct. 1988.

4. Mueller, J. and Micci, M., "Investigation of Propagation Mechanism and Stabilization of a Microwave Heated Plasma," AIAA Paper 89-2377, July 1989.

5. Sullivan, D. J. and Micci, M. M., "The Effect of Molecular Propellants on the Performance of a Resonant Cavity Electrothermal Thruster," AIDAA/AIAA/DGLR/JSASS 22nd International Electric Propulsion Conference, IEPC Paper 91-034, Oct. 1991. 
6. Arata, Y., Miyake, S., and Kobayashi, A., "High Power Microwave Discharge in Atmospheric Hydrogen Gas Flow," Journal of the Physical Society of Japan, Vol. 44, Mar. 1978, pp. 998-1003.

7. Power, J. L. and Chapman, R. A., "Development of a High Power Microwave Thruster, with a Magnetic Nozzle, for Space Applications," NASA TM-102321, Aug. 1989.

8. Balanis, C. A., Advanced Engineering Electromagnetics, John Wiley \& Sons, Inc., New York, 1989.

9. Collin, R. A., Field Theory of Guided Waves, McGrawHill Book Co., Inc., New York, 1960, pp. 258-271.

10. Frasch, L. L., "An Experimental and Theoretical Study of a Microwave Cavity Applicator Loaded with Lossy Materials," Ph.D. dissertation, Michigan State University, E. Lansing, MI, 1987.

11. Nasser, E., Fundamentals of Gaseous Ionization and Plasma Electronics, John Wiley \& Sons, Inc., New York, 1971.

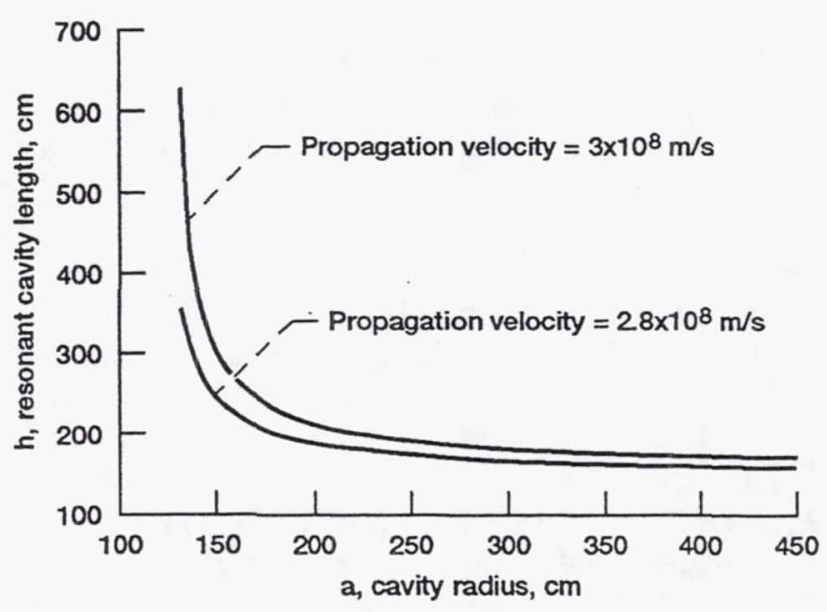

Figure 1. $-\mathrm{TM}_{011}$ mode resonant cavity length as a function of radius at $915 \mathrm{MHz}$, showing dependence on propagation velocity.
12. Power, J. L., "Microwave Electrothermal Propulsion for Space," IEEE Transactions on Microwave Theory and Techniques, Vol. 40, No. 6, June 1992, pp. 1179-1191.

TABLE I.-MAXIMUM POWER CONDITIONS TESTED

\begin{tabular}{|l|r|r|r|}
\hline Gas & $\mathrm{He}$ & $\mathrm{N}_{2}$ & $\mathrm{H}_{2}$ \\
\hline TM mode & 012 & 011 & 012 \\
\hline Maximum applied power (kW) & 3.5 & 11.2 & 4.2 \\
\hline $\begin{array}{l}\text { Coupling efficiency at } \\
\text { maximum power (\%) }\end{array}$ & 75 & 54 & 86 \\
\hline Maximum pressure (kPa) & 69 & 69 & 28 \\
\hline (psia) & 10 & 10 & 4 \\
\hline Maximum flowrate (slpm) & 31 & 19 & 22 \\
\hline
\end{tabular}

Notes:

- all plasmas in spike condition;

- coupling efficiencies limited by input power probe insertion range;

$\cdot \mathrm{H}_{2}$ testing limited by discharge tube heating.

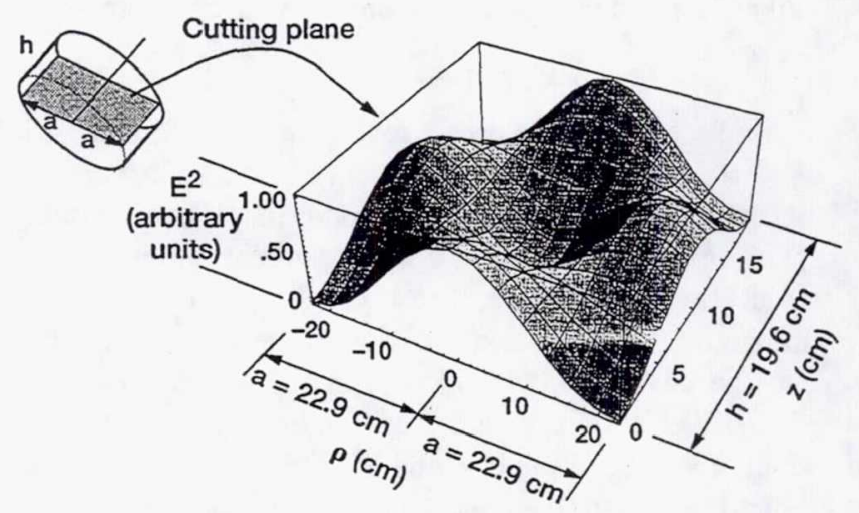

(a) $\mathrm{TM}_{011}$ mode.

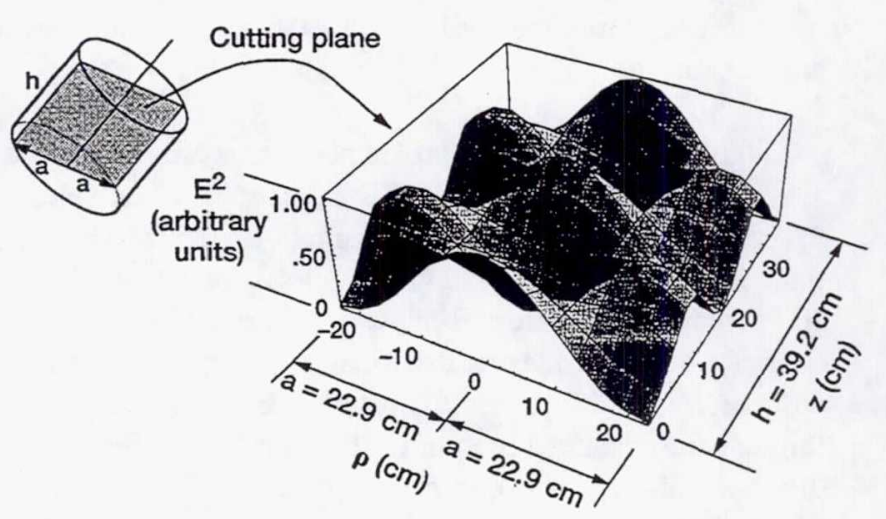

(b) $\mathrm{TM}_{012}$ mode.

Figure 2.-Resonant electric power density contour. 


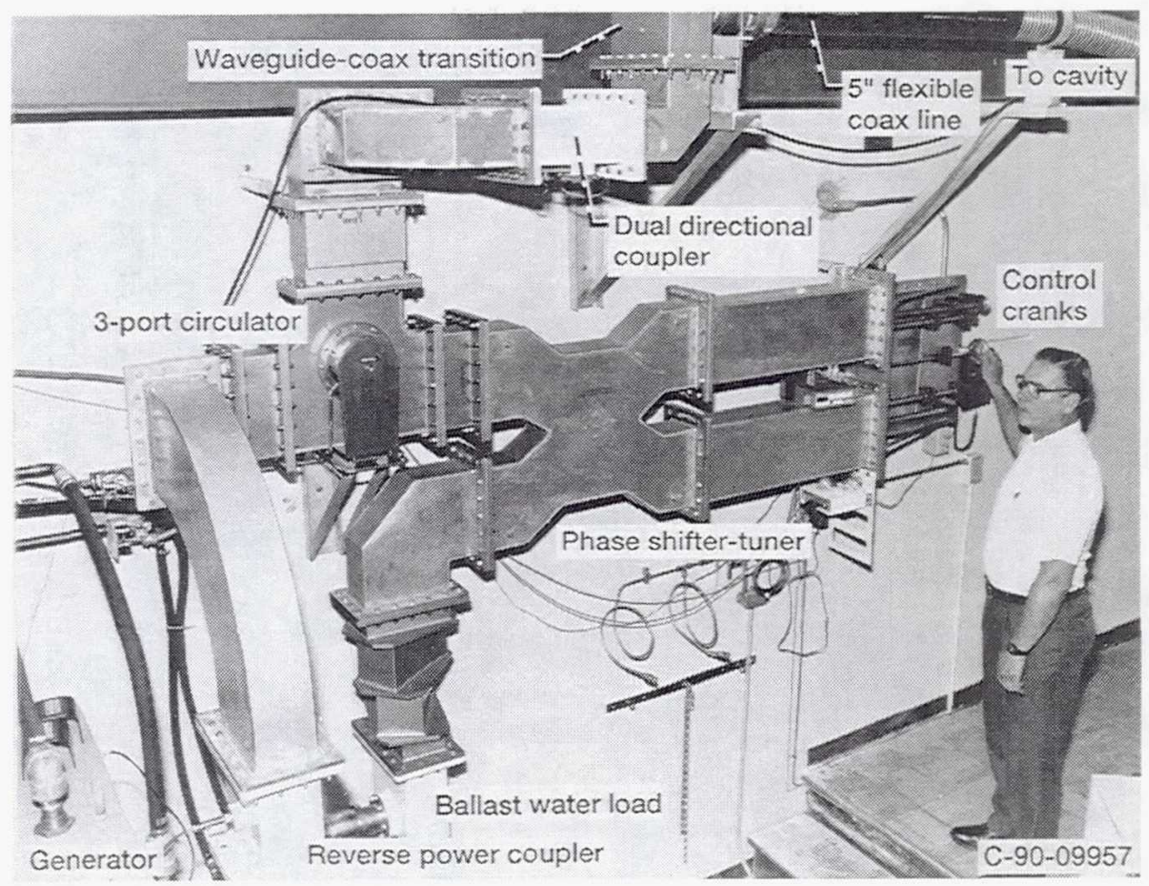

Figure 3.-Microwave power delivery circuit.

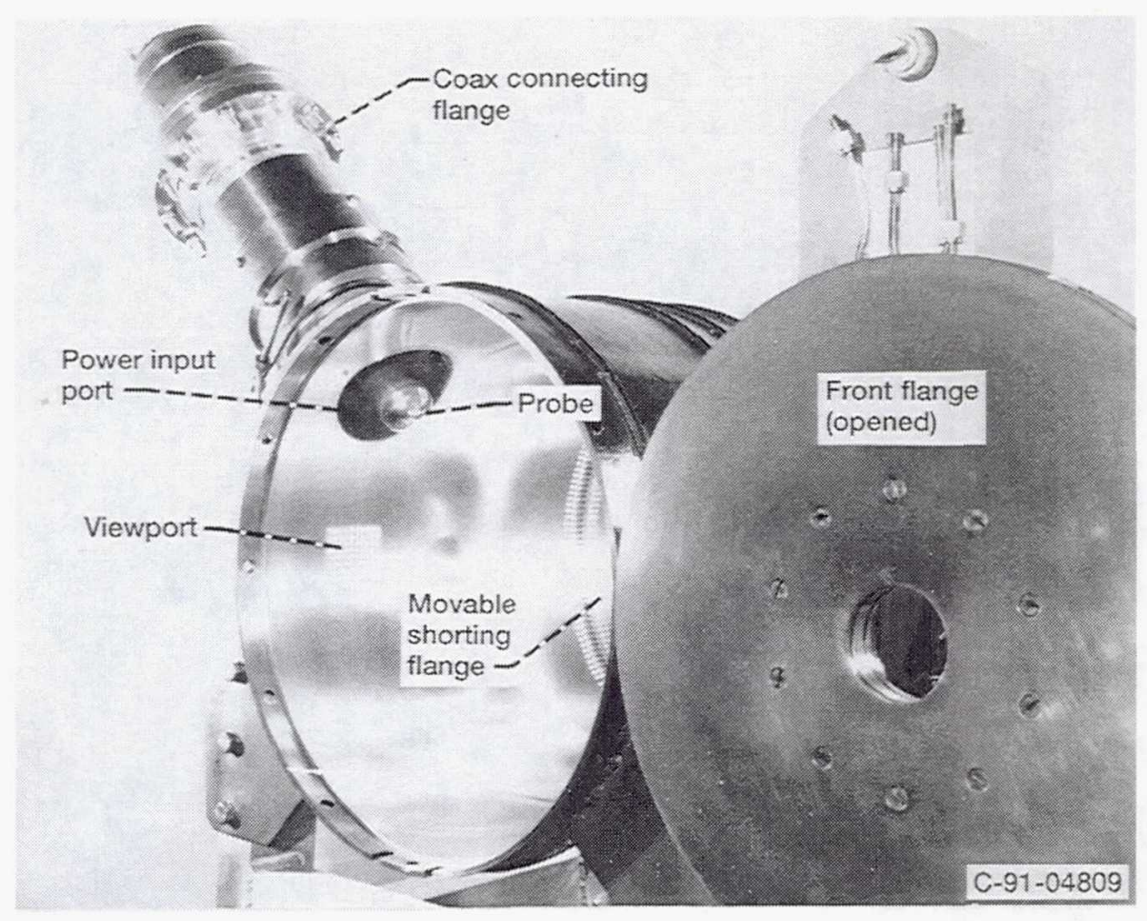

Figure 4.-Microwave cavity. 


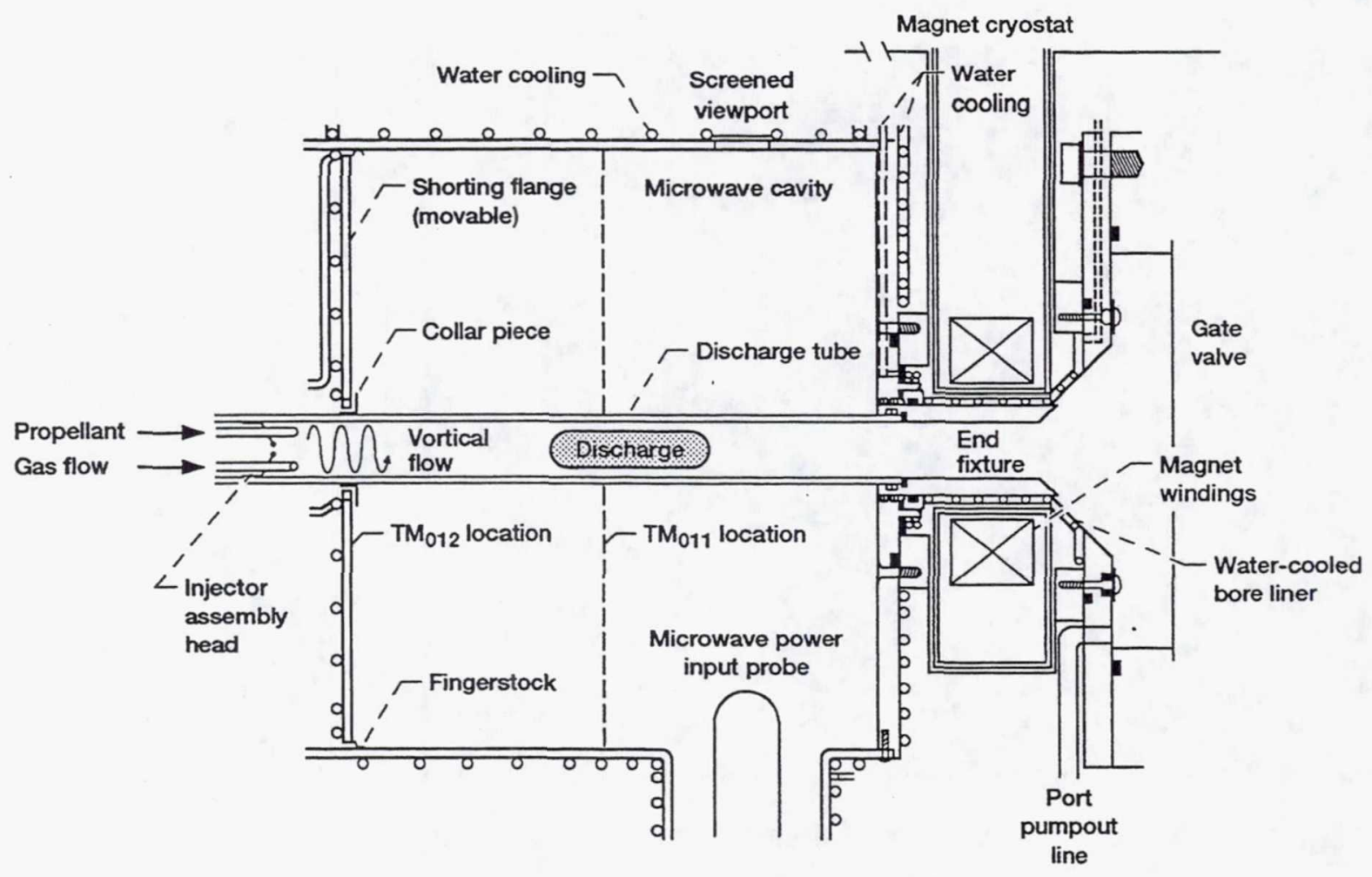

Figure 5.-Microwave cavity/magnet configuration.

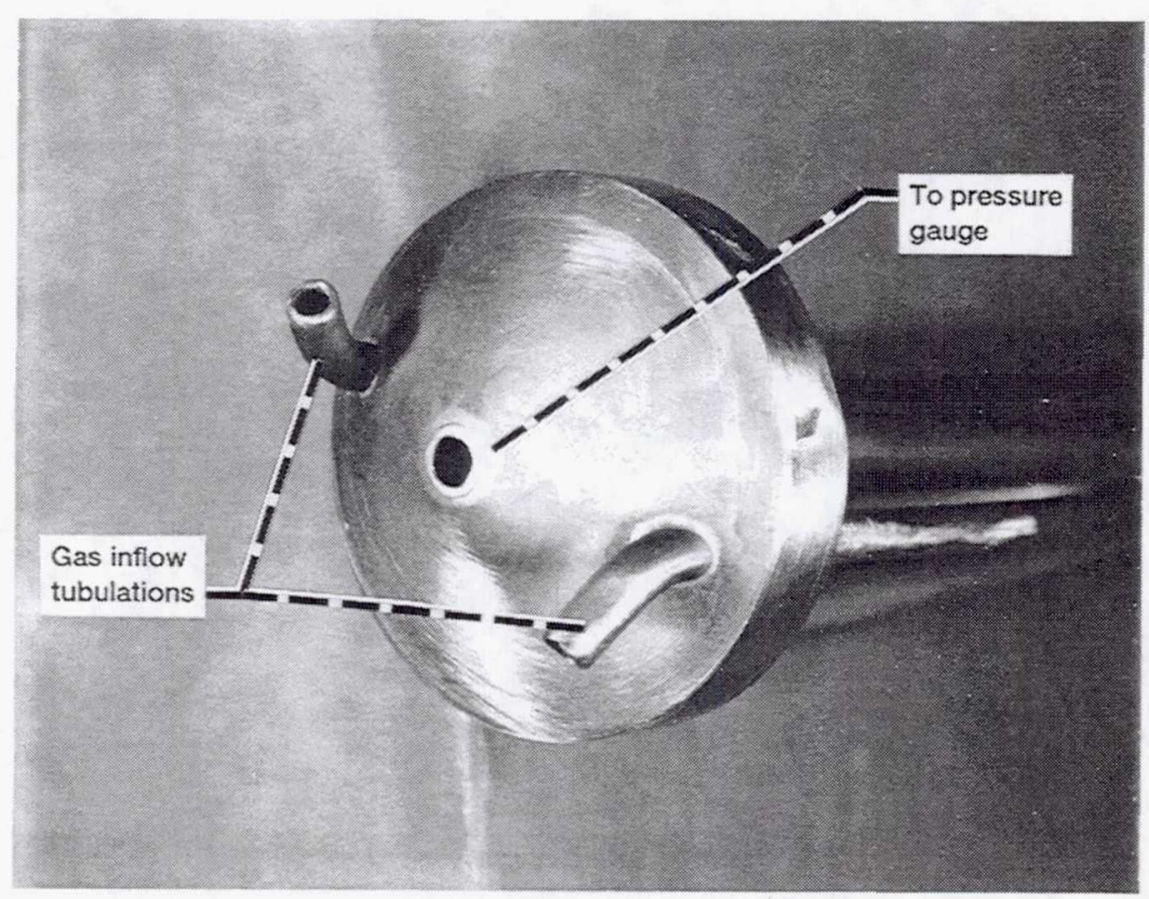

Figure 6.-Injector assembly head. 


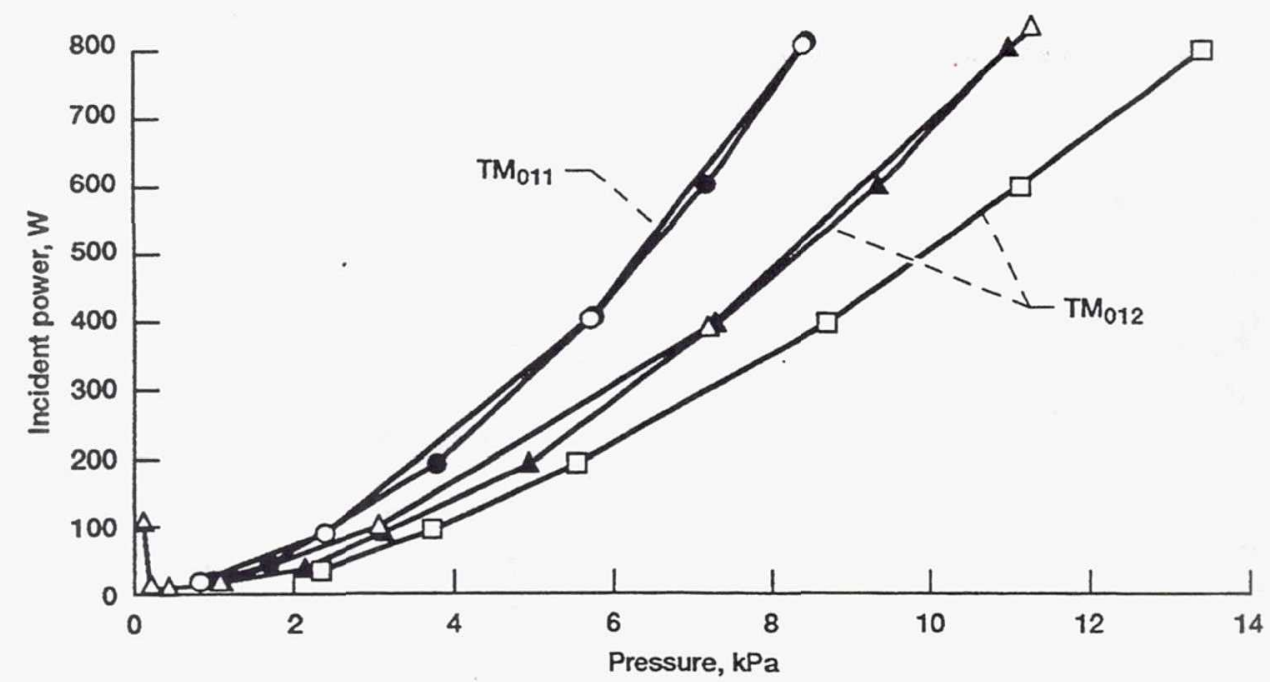

(a) Breakdown in helium.

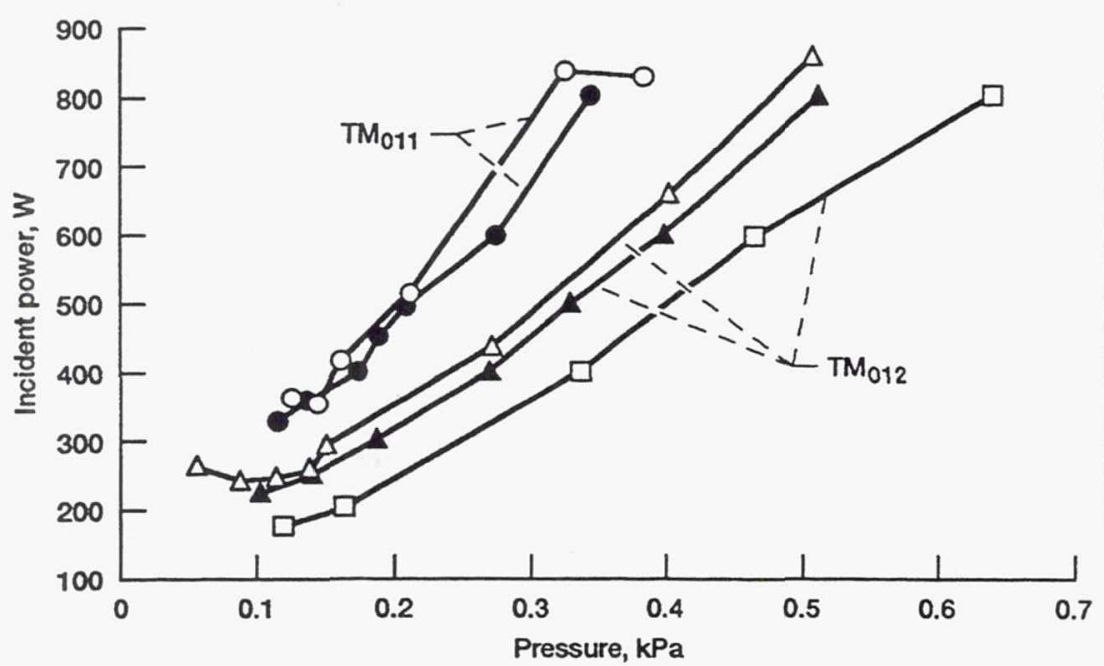

\section{Legend for all plots}

- Constant pressure, increasing power, probe $=4.45 \mathrm{~cm} ; \mathrm{TM}_{011}$ mode

- Constant power, reducing pressure; probe $=4.45 \mathrm{~cm} ; \mathrm{TM}_{011}$ mode

$\Delta$ Constant pressure, increasing power, probe $=4.45 \mathrm{~cm} ; \mathrm{TM}_{012}$ mode

$\Delta$ Constant power, reducing pressure; probe $=4.45 \mathrm{~cm} ; \mathrm{TM}_{012}$ mode

$\square$ Constant power, reducing pressure; probe $=3.18 \mathrm{~cm} ; \mathrm{TM}_{012}$ mode

(b) Breakdown in nitrogen.

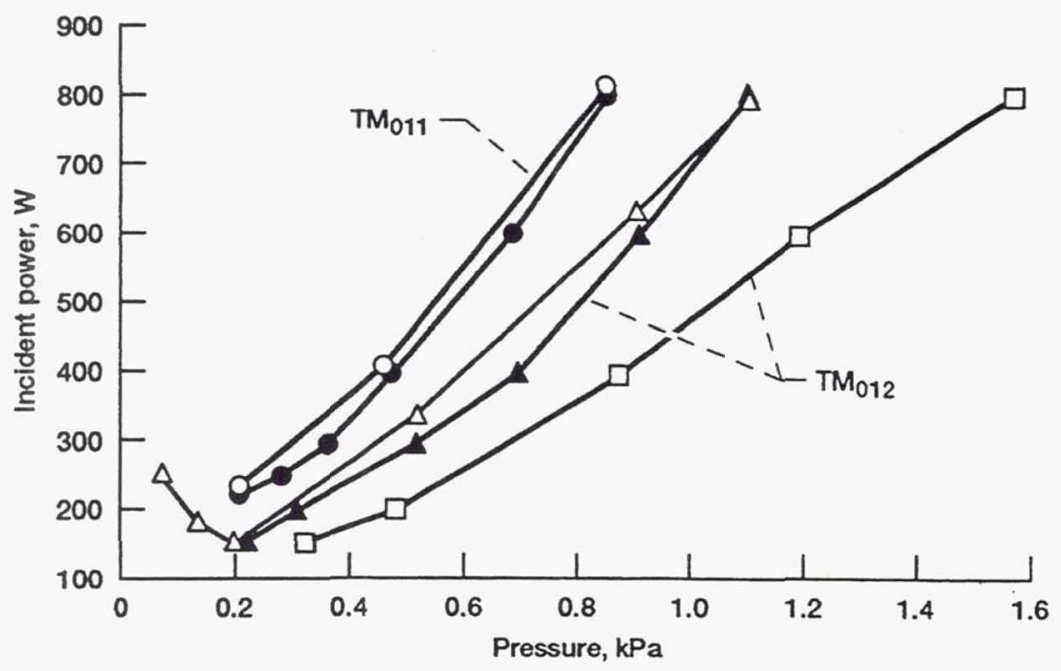

(c) Breakdown in hydrogen.

Figure 7.-Microwave breakdown conditions for helium, nitrogen, and hydrogen. 


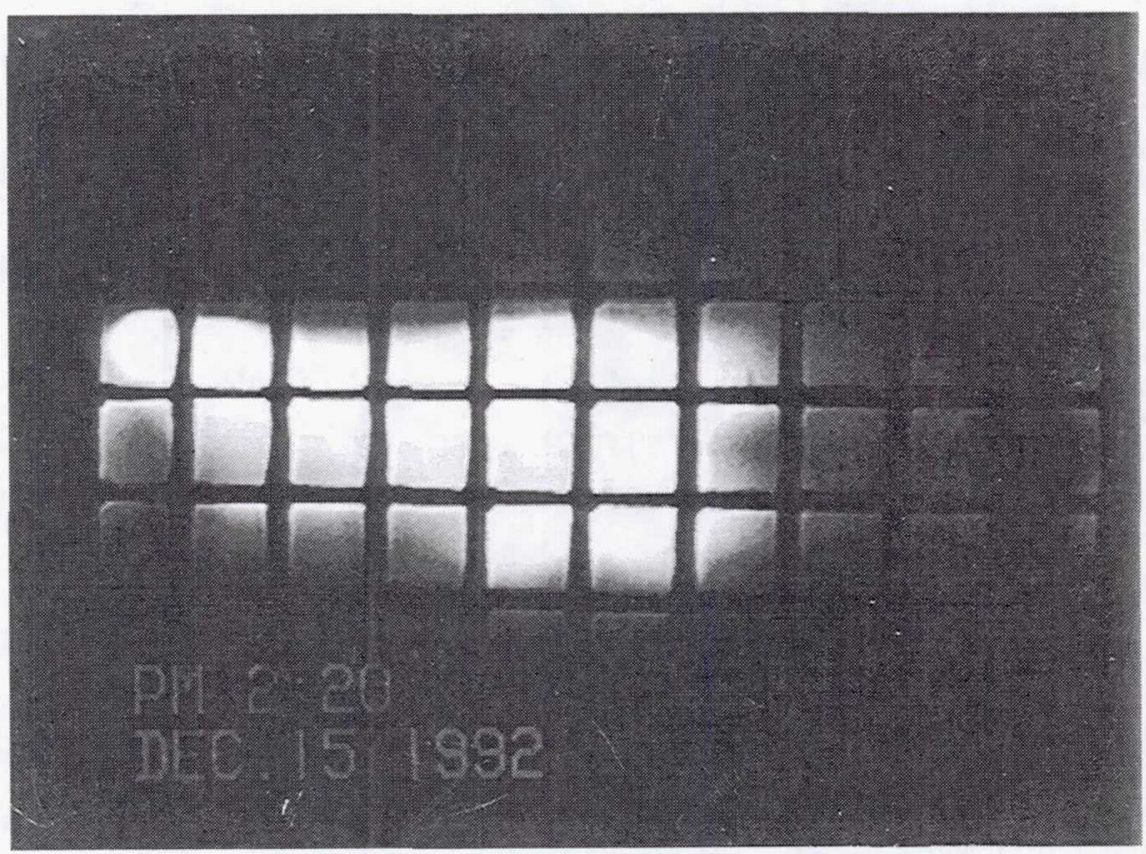

(a) Unsymmetric, wall-attached plasma.

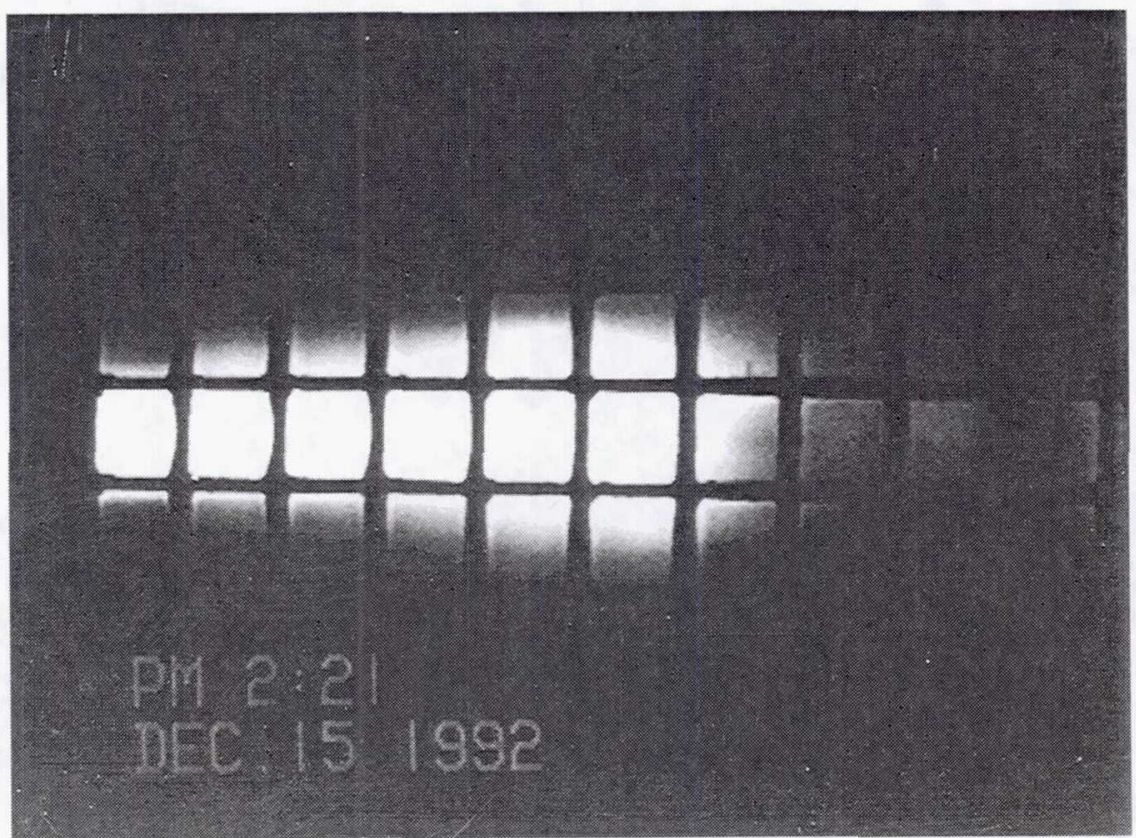

(b) Spike plasma.

Figure 8.-Plasma conditions. 


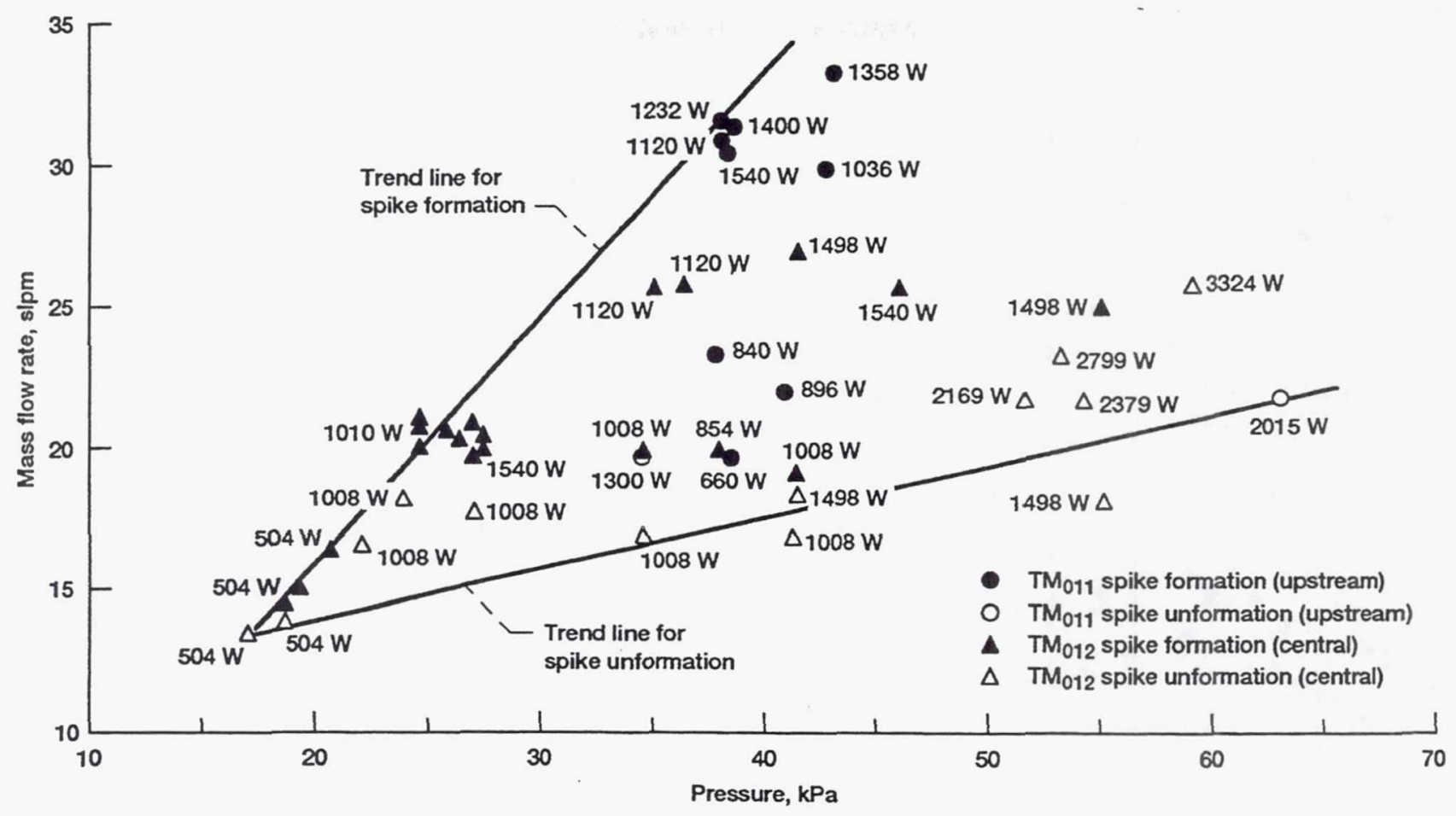

Figure 9.-Spike plasma formation and unformation in $\mathrm{He}$.

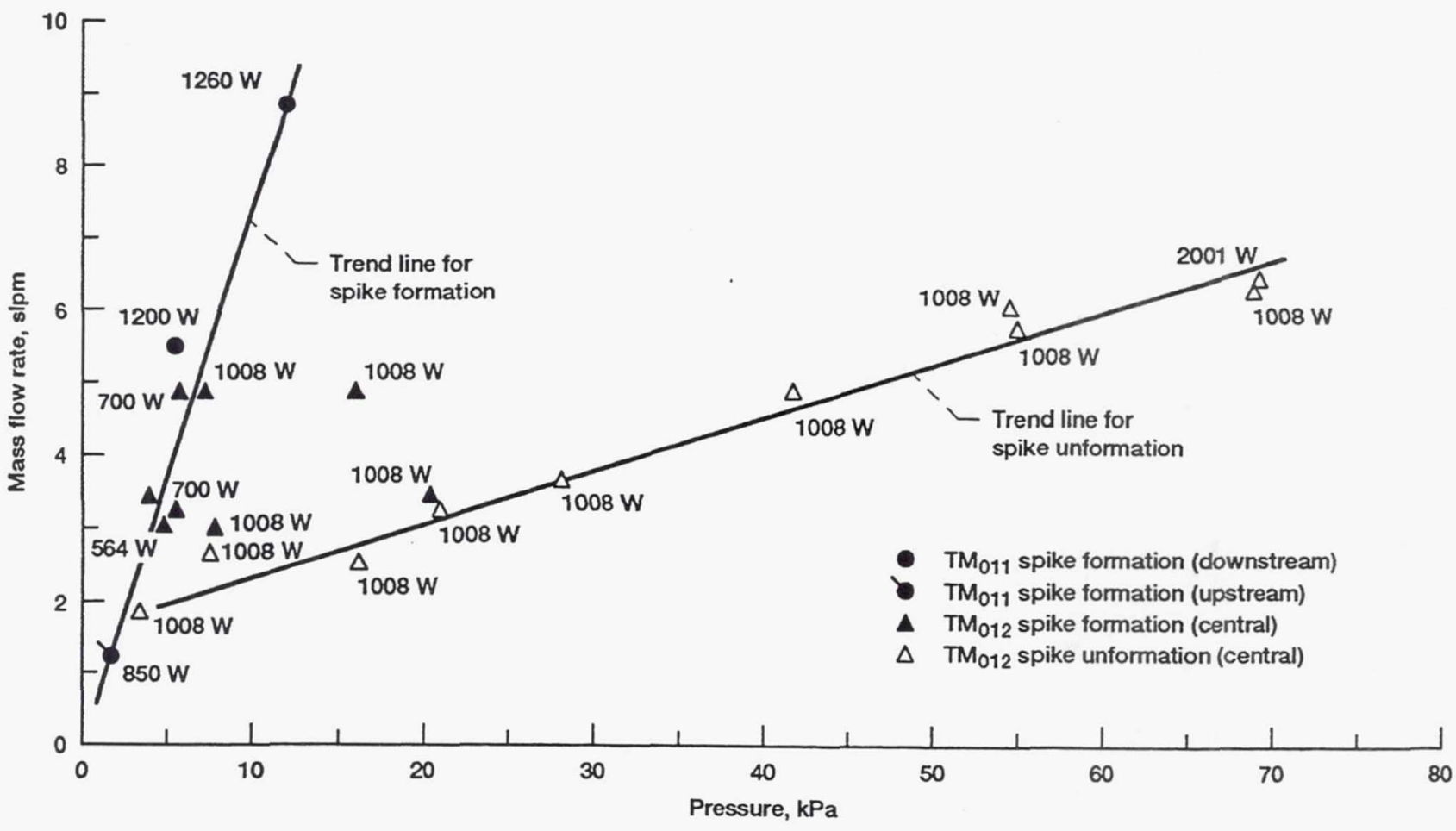

Figure 10. Spike plasma formation and unformation in $\mathrm{N}_{2}$. 
Page intentionally left blank 


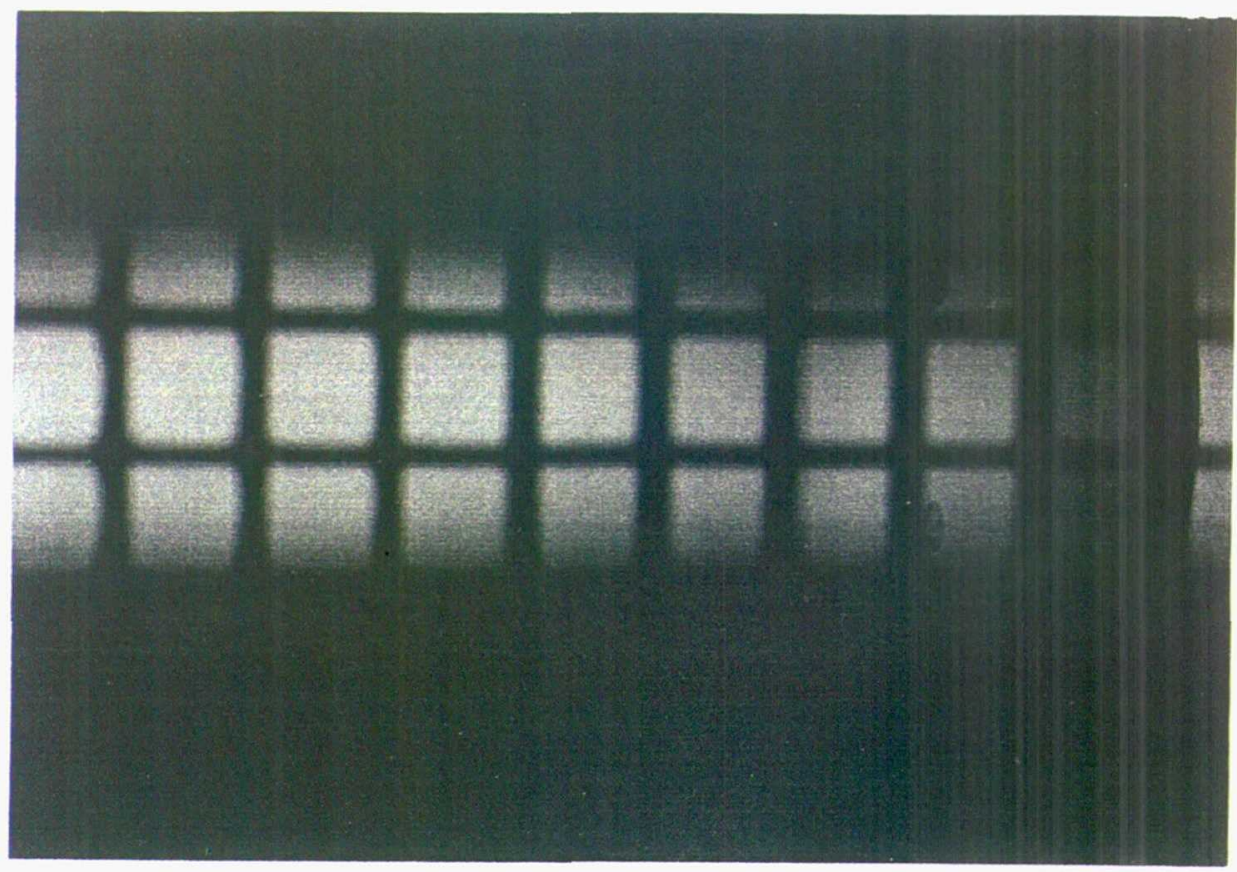

(a) No magnetic field.

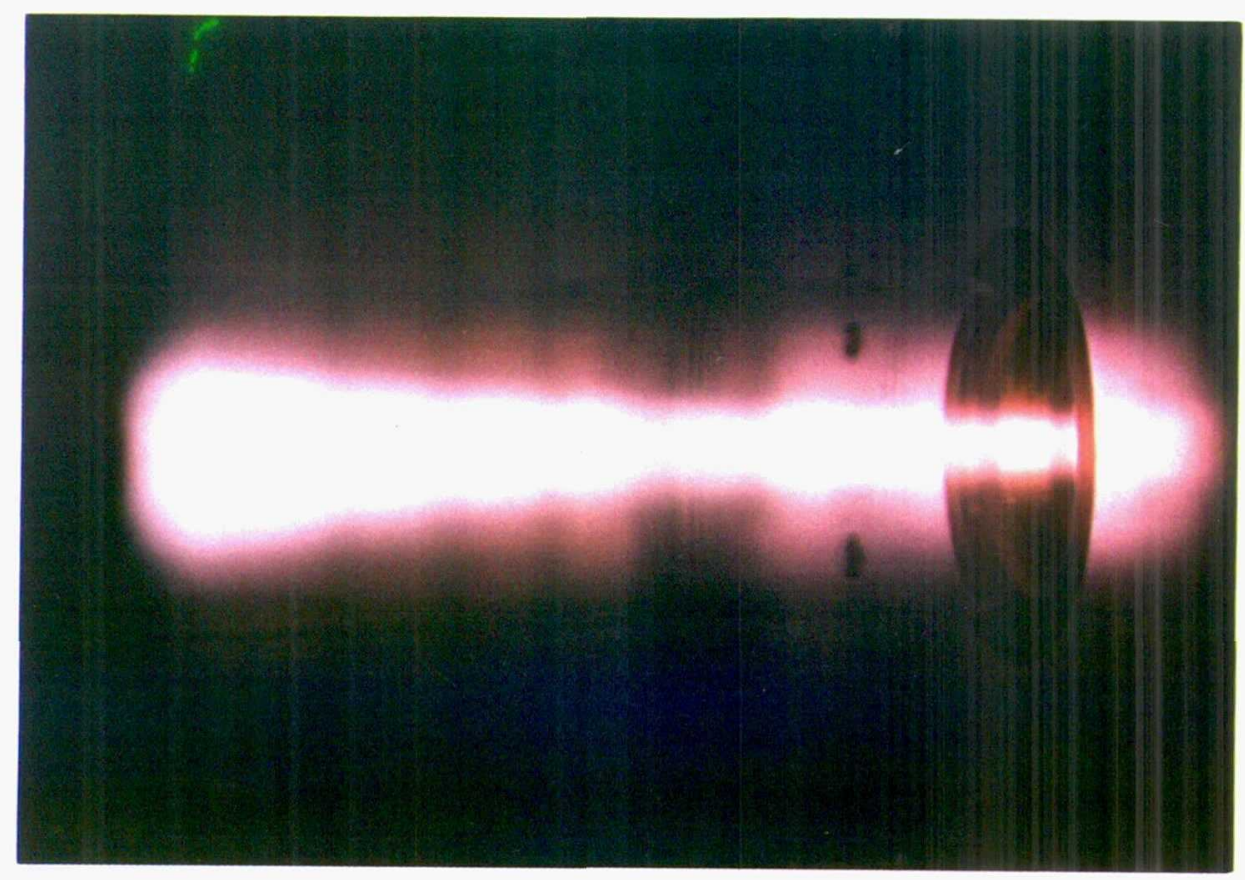

(b) $80 \mathrm{~A}$ magnetic field.

Figure 11.-Magnetic nozzle effect on low pressure He plasma. 
Public reporting burden for this collection of information is estimated to average 1 hour per response, including the time for reviewing instructions, searching existing data sources, gathering and maintaining the data needed, and completing and reviewing the collection of information. Send comments regarding this burden estimate or any other aspect of this collection of information, including suggestions for reducing this burden, to Washington Headquarters Services, Directorate for Information Operations and Reports, 1215 Jefforson Davis Highway, Suite 1204, Arlington, VA 22202-4302, and to the Office of Management and Budget, Paperwork Reduction Project (0704-0188), Washington, DC 20503.

\section{\begin{tabular}{l|l|l|}
\hline 1. AGENCY USE ONLY (Leave blank) & 2. REPORT DATE & 3. REPORT TYPE AND DATES COVERED
\end{tabular}}

\begin{tabular}{l|l|l} 
June 1993 & Technical Memorandum \\
\hline
\end{tabular}

\section{TITLE AND SUBTITLE}

Preliminary Investigation of High Power Microwave Plasmas for Electrothermal Thruster Use

6. AUTHOR(S)

John L. Power and Daniel J. Sullivan

\section{FUNDING NUMBERS}

WU-506-42-31

\section{PERFORMING ORGANIZATION NAME(S) AND ADDRESS(ES)}

National Aeronautics and Space Administration

Lewis Research Center

Cleveland, Ohio 44135-3191

8. PERFORMING ORGANIZATION REPORT NUMBER

E-7917

9. SPONSORING/MONITORING AGENCY NAME(S) AND ADDRESS(ES)

National Aeronautics and Space Administration

Washington, D.C. 20546-0001
10. SPONSORING/MONITORING AGENCY REPORT NUMBER

NASA TM-106207

AIAA-93-2106

\section{SUPPLEMENTARY NOTES}

Prepared for the 29th Joint Propulsion Conference and Exhibit cosponsored by the AIAA, SAE, ASME, and ASEE, Monterey, California, June 28-30, 1993. Responsible person, John L. Power, (216) 433-8687.

12a. DISTRIBUTION/AVAILABILITY STATEMENT

12b. DISTRIBUTION CODE

Unclassified - Unlimited

Subject Category 20

13. ABSTRACT (Maximum 200 words)

Results are reported from preliminary tests to evaluate the high power microwave electrothermal thruster (MET) concept, which employs a free-floating plasma discharge maintained by applied CW microwave power to heat a propellant gas flow. Stable plasmas have been created and maintained in helium $(\mathrm{He})$, nitrogen $\left(\mathrm{N}_{2}\right)$, and hydrogen $\left(\mathrm{H}_{2}\right)$ as propellants in both the $\mathrm{TM}_{011}$ and $\mathrm{TM}_{012}$ modes at discharge pressures from $10 \mathrm{~Pa}$ to $69 \mathrm{kPa}$. Reproducible starting conditions of pressure and power have been documented for all the plasmas. Vortical inflow of the propellant gas was observed to cause the formation of on-axis "spike" plasmas. The formation and unformation conditions of these plasmas were studied. Operation in the spike plasma condition enables maximum power absorption with minimum wall heating and offers maximum efficiency in heating the propellant gas. In the spike condition, plasmas of the three propellant gases were investigated in an open channel configuration to a maximum applied power level of $11.2 \mathrm{~kW}$ (in $\mathrm{N}_{2}$ ). Microwave power coupling efficiencies of over $90 \%$ were routinely obtained at absorbed power levels up to $2 \mathrm{~kW}$. Magnetic nozzle effects were investigated with a superconducting solenoidal magnet applying a high magnetic field to the plasmas in and exiting from the discharge tube.

\section{SUBJECT TERMS}

Microwave; Plasma; Electrothermal; Electric propulsion OF REPORT Unclassified
18. SECURITY CLASSIFICATION OF THIS PAGE Unclassified
19. SECURITY CLASSIFICATION OF ABSTRACT Unclassified
15. NUMBER OF PAGES

19

16. PRICE CODE

$\mathrm{A} 03$ 